\title{
Los derechos laborales colectivos y las relaciones laborales transnacionales: competencia judicial y ley aplicable*
}

\author{
Collective labor rights and transnational labor relations: \\ international jurisdiction and applicable law
}

\author{
Pilar Fernández Artiach ${ }^{* *}$ \\ Universitat de València \\ ORCID: 0000-0003-4025-1691
}

Recibido: 4/8/19

Aceptado: 11/11/19

doi: https://doi.org/10.20318/labos.2020.5296

Resumen: La solución de los conflictos de jurisdicciones y de leyes que pueda provocar el ejercicio extraterritorial de los derechos laborales colectivos carece de tratamiento por parte del legislador comunitario, al no haber introducido en las normas existentes en materia de determinación de la competencia judicial y de la legislación aplicable los criterios de conexión necesarios para determinar cuál pueda ser el órgano judicial competente para conocer del conflicto (conflicto de jurisdicciones) y qué ordenamiento jurídico nacional resulta aplicable al asunto (conflicto de leyes). Con este trabajo se busca aportar soluciones razonadas en los casos en los que no existen tales criterios de conexión, así como argumentar sobre la posible aplicación, en ciertos casos, de las normas comunitarias existentes en la actualidad.

Palabras clave: derechos laborales colectivos, relación transnacional, conflicto de jurisdicciones, conflicto de leyes.

Abstract: $\quad$ The solution to the conflicts of jurisdictions and laws caused by the extraterritorial exercise of collective labor rights lacks treatment by the EU legislator, since it has not introduced into the existing norms regarding the determination of judicial competence and applicable legislation the necessary connection criteria to determine which the competent judicial body may be to hear about the conflict (conflict of jurisdictions) and what national legal order is applicable to the matter (conflict of laws). This work seeks to provide reasonable solutions in cases where there are no such connection criteria, as well as to argue about the possible application, in certain cases, of the existing EU norms.

Keywords: collective labor rights, transnational relationship, conflict of jurisdictions, conflict of laws.

\footnotetext{
*pilar.fernandez@uv.es

"Este trabajo se ha realizado en el marco del Proyecto de Investigación "Las relaciones laborales internacionales: jurisdicción competente y ley aplicable en materia de contrato individual de trabajo, derechos colectivos y Seguridad Social” (DER2016-77772-P).
} 


\section{Introducción}

En las últimas décadas, la globalización de los mercados económicos y de trabajo ha incrementado la complejidad de las relaciones laborales, incorporando en muchas de ellas un elemento internacional o de extranjería que puede recaer, de manera aislada o combinando los distintos factores, bien en la figura del empleador, bien en la figura del trabajador, o bien en el lugar de la prestación de los servicios. En los casos en que surge un conflicto entre empleador y trabajador, la presencia de un elemento internacional en la relación de trabajo suele generar problemas para determinar tanto la jurisdicción competente para conocer de la disputa, como la ley que haya de aplicarse al fondo del litigio para resolver el conflicto. Cuando el conflicto se refiere al ejercicio extraterritorial de derechos laborales colectivos, sea de forma individual o sea de forma colectiva, estos problemas se acrecientan.

El objetivo del presente trabajo es tan sólo analizar la dimensión de los problemas de determinación de la competencia judicial internacional y determinación de la ley aplicable en aquellos supuestos conflictivos de ejercicio individual y colectivo de los derechos laborales colectivos clásicos (libertad sindical, representación de los trabajadores, negociación colectiva y conflicto colectivo, incluyendo a la huelga como medida de conflicto) en relaciones de trabajo transnacionales y/o plurilocalizadas. Del análisis de la jurisprudencia existente se deduce que una mayoría de supuestos conflictivos aparece cuando los trabajadores participan en alguna modalidad de acción de conflicto colectivo de carácter transnacional, aunque también los hay concernientes al ejercicio de otros derechos laborales colectivos.

\section{Determinación de la jurisdicción competente en materia de derechos laborales colectivos}

\subsection{Normativa comunitaria: el Reglamento (CE) no 1215/2012 del Parlamento Europeo y del Consejo, de 12 de diciembre, relativo a la competencia judicial, el reconocimiento y la ejecu- ción de resoluciones judiciales en materia civil y mercantil, y el Convenio de Lugano de 30 de octubre de 2007}

Para las partes de un conflicto laboral, la determinación de cuál haya de ser el órgano judicial ante el que interponer la demanda es especialmente relevante en aquellos casos en los que existe en la relación un elemento de extranjería.

En el ámbito comunitario, pues es desde esta perspectiva desde la que se va a realizar el estudio, el Reglamento (CE) no 1215/2012 del Parlamento Europeo y del Consejo, de 12 de diciembre, relativo a la competencia judicial, el reconocimiento y la ejecución de resoluciones judiciales en materia civil y mercantil (conocido también como Bruselas $I$ bis), que entró en vigor el 10 de enero de 2015 sustituyendo al anterior Reglamento (CE) no 44/2001 del Consejo, de 22 de diciembre (Bruselas I), de necesaria aplicación por los Tribunales españoles y complementado por el Convenio de Lugano II, de 30 de octubre de $2007^{1}$, incluye solamente de manera expresa al "contrato individual de trabajo" dentro de su ámbito de aplicación (sección 5, arts. 20 y ss.), por lo que, a sensu contrario, la mayoría de la doctrina científica entiende excluidos los litigios referidos a las relaciones colectivas de trabajo ${ }^{2}$, aun cuando estos no se encuentren entre las materias expresamente exceptuadas en su artículo 1.2, lo que sí ocurre, por ejemplo, con la Seguridad Social o el arbitraje.

\footnotetext{
${ }^{1}$ Convenio aplicable en principio a los Estados miembros de la Unión Europea, incluyendo a Dinamarca, y a los Estados miembros de la Asociación Europea de Libre Comercio (Suiza, Noruega, Islandia) y cuya regulación de los foros competentes en relación con el contrato individual de trabajo es idéntica a la del Reglamento Bruselas I Bis.

${ }^{2}$ Por todos, PALAO MORENO, G, "La comunidad europea y el contrato individual de trabajo internacional: aspectos de jurisdicción competente y de ley aplicable”, Revista Sequencia, n 52, 2006, pág. 39.
} 
En esa ausencia de tratamiento por el Reglamento Bruselas I bis y el Convenio de Lugano II influye, sin duda, el hecho de que la regulación de los derechos colectivos y de las relaciones colectivas de trabajo ha estado tradicionalmente en manos de los Estados, conforme al clásico principio de territorialidad que gobierna los ordenamientos jurídicos laborales nacionales. Ni siquiera la Unión Europea (UE en adelante), como entidad supranacional, posee competencias legislativas en algunos aspectos de la materia (art. 153.5 TFUE3). Desde que empieza a legislarse sobre el trabajo, los Estados se han encargado de regular los derechos laborales colectivos a través de su legislación nacional pensando en su ejercicio en un territorio determinado, que es el del propio Estado. No ha de sorprender, por tanto, que la posibilidad de entablar un proceso relacionado con el ejercicio extraterritorial de derechos colectivos no se contemple, ni se establezcan reglas de conflicto para determinar el órgano judicial competente para resolver tales conflictos.

Sin embargo, como es habitual, la realidad ha desbordado a la teoría en este punto, de modo que, en un mundo global, el derecho adscrito a un territorio concreto pierde sentido y necesita adaptarse a un espacio en el que, de una parte, existen relaciones de trabajo prestadas de modo simultáneo para una misma empresa pero sometidas a ordenamientos jurídicos distintos, pues se trata de empresas que actúan internacionalmente, bien sea deslocalizando o bien sea externalizando y subcontratando parte de su actividad ${ }^{4}$, de manera que, al llevarse a cabo el proceso de producción en Estados distintos, los sistemas jurídicos a los que se someten las relaciones de trabajo en la empresa o en su cadena global de producción son también diferentes; y de otra, un espacio en el que existen organizaciones nacionales o internacionales de trabajadores que convocan acciones de conflicto colectivo de carácter transnacional, o que convocan acciones de solidaridad en las que el lugar donde estas se realizan no coincide necesariamente con el lugar donde quiere producirse, o se produce, el daño. De modo tal que, en la práctica, en estos casos se plantea el problema de determinar cuál sería el órgano judicial competente para resolver posibles conflictos de carácter colectivo que surjan en ese espacio global si se judicializan, o los conflictos generados por la participación individual en acciones colectivas.

En el Reglamento Bruselas I bis se podrían haber incorporado reglas de conflicto para la determinación de la competencia judicial en estos casos pero, al no haberse hecho, y como sucede en aquellos supuestos en que no cabe aplicar el Reglamento, el cual utiliza como criterio general de aplicación espacial de sus normas reguladoras de la competencia judicial internacional el domicilio del demandado en un Estado miembro de la $U E^{5}$, se ha de recurrir en estos casos a su propio artículo 6.1, que remite a la aplicación de las normas de competencia judicial internacional de los sistemas autónomos de los Estados correspondientes, sean estos miembros de la UE o no, las cuales servirán para determinar si el órgano judicial nacional ante el que se sustancia el asunto es competente o no para conocer del mismo.

${ }^{3}$ Como es por todos conocido, excluye de las competencias de la UE, entre otros, los derechos de asociación y sindicación, el derecho de huelga y el derecho al cierre patronal.

${ }^{4}$ GORDO GONZALEZ, L., "Una óptica nacional: los derechos de participación de los trabajadores en las empresas multinacionales; la recepción de la transnacionalización”, En: QUINTERO LIMA, M.G. (Dir.), La Globalización económica y el Futuro del Trabajo: algunas reflexiones, Universidad Carlos III de Madrid, 2018, págs. 48-52, define la empresa trasnacional como aquella que emplea trabajadores en varios Estados a través de una estructura de dominación -donde la empresa matriz controla a las filiales mediante vínculos societarios o contractuales- o de coordinación -donde no hay una sociedad dominante sino que todas se guían en su actuar por objetivos comunes a medio y largo plazo-, caracterizándose por la facilidad para eludir los controles estatales sobre sus acciones; por la distancia de las filiales o las empresas proveedoras con el lugar donde se toman las decisiones; por la necesidad de armonizar culturas y tradiciones diferentes al trabajarse en Estados distintos con sistemas no sólo jurídicos sino también culturales diversos; y por la pérdida de influencia de los trabajadores y sus representantes, cuando existen, en la toma de decisiones, al estar atomizada la representación por trabajarse mediante estructuras empresariales en red.

${ }^{5}$ Véase al respecto AGUILAR GRIEDER, H., "Alcance de la regulación europea relativa a la competencia judicial internacional en materia civil y mercantil en el marco del nuevo Reglamento Bruselas I bis (1215/2012): una apuesta parcialmente frustrada", Revista Aranzadi Doctrinal, no 9, 2015. También, MENÉNDEZ SEBASTIÁN, P., "Competencia judicial en el contrato laboral con elemento extranjero", Revista del Ministerio de Empleo y Seguridad Social, no 132, 2017, págs. 79 y ss. 
Por su parte, el Tribunal de Justicia de la Unión Europea (en adelante, TJUE) ha venido admitiendo demandas por cuestiones litigiosas referidas a las relaciones colectivas de trabajo con elemento de extranjería ${ }^{6}$, evidentemente no por tratarse de materia laboral colectiva, que estaría excluida, sino al considerar que la responsabilidad por los daños ocasionados en estos supuestos, que permite entrar a analizar a su vez la legalidad de la acción colectiva, debe calificarse como "materia delictual o cuasidelictual", que sí se encuentra incluida expresamente en el Reglamento Bruselas I Bis dentro de los foros especiales (artículo 7.2), permitiéndose en estos casos demandar a una persona domiciliada en un Estado miembro en otro distinto, concretamente ante los tribunales del lugar donde se haya producido o pueda producirse el hecho dañoso ${ }^{8}$.

Para comprender las razones que llevan al TJUE a admitir este tipo de demandas hay que detenerse, siquiera de forma breve, en el análisis de los términos "materia delictual o cuasidelictual" del artículo 7.2 del Reglamento. Este dispone expresamente que "una persona domiciliada en un Estado miembro podrá ser demandada en otro Estado miembro: (...) 2) en materia delictual o cuasidelictual, ante el órgano jurisdiccional del lugar donde se haya producido o pueda producirse el hecho dañoso". Este foro concurre con la posibilidad de sumisión expresa o tácita y de acción del foro general del domicilio del demandado?.

Entiende el TJUE ${ }^{10}$, y así lo ha resaltado la doctrina internacional privatista ${ }^{11}$, que el legislador comunitario está contraponiendo, dentro de los foros especiales, la materia contractual del artículo $7.1^{12}$ a la materia delictual o cuasidelictual del artículo 7.2, de manera que esta última se considera equivalente a "materia extracontractual"13. El TJUE, en interpretación autónoma y uniformadora del concepto ${ }^{14}$, entiende en su sentencia de 13 de Marzo de 2014 (asunto C-548/12, Marc Brogsit-

${ }^{6}$ Véase FOTINOPOULOU BASURKO, O., El proceso laboral internacional en el Derecho comunitario, Consejo Económico y Social de Andalucía, 2008, págs. 78 y ss., donde hace referencia en este sentido a la STJUE de 12 de noviembre de 2007 (asunto C-438/05, Viking).

${ }^{7}$ Así, por ejemplo, la STJUE de 5 de Febrero de 2004, (asunto C-18/2002, Torline), sobre responsabilidad por daños derivados de conflicto colectivo entablado frente a un empresario marítimo, señala en su apartado 28 que "constituye "materia delictual o cuasi delictual» una acción judicial sobre la legalidad de una acción colectiva cuya competencia corresponde exclusivamente, conforme al Derecho del Estado contratante de que se trate, a un órgano jurisdiccional distinto al que es competente para conocer de las demandas de indemnización de los daños y perjuicios causados por dicha acción colectiva".

${ }^{8}$ Conforme interpretación realizada por el TJUE en diversas sentencias (véanse los asuntos Bier, apartado 11; Dumez France y Tracoba, apartado 17; Shevill y otros, apartado 19; Marinari v. Lloyds Bank, apartado 10; Torline, apartado 40), "esta regla de competencia especial, cuya elección depende de una opción del demandante, se basa en la existencia de una conexión particularmente estrecha entre el litigio y otros Tribunales distintos de los del domicilio del demandado, que justifique la atribución de competencia a dichos órganos jurisdiccionales en aras de una buena administración de la justicia, así como de una sustanciación adecuada del proceso".

${ }^{9}$ Véase esta opinión en FERNANDEZ ROZAS, J.C. y SANCHEZ LORENZO, S., Derecho Internacional Privado, Ed. Civitas, $10^{\mathrm{a}}$ ed., 2018, pág. 500.

${ }^{10}$ Sostiene el TJUE en la sentencia de 27 de septiembre de 1988 (asunto C-189/1987, Kalfelis Schröder), que "Para garantizar una solución uniforme en todos los Estados miembros, conviene admitir que el concepto de "en materia de delitos o cuasidelitos» comprende toda demanda que se dirija a exigir la responsabilidad de un demandado y que no esté relacionada con la "materia contractual" en el sentido del apartado 1 del artículo 5", refiriéndose en aquel momento al Convenio de Bruselas de 1968, precedente de los Reglamentos Bruselas I y Bruselas I bis.

${ }^{11}$ Puede verse, por todos, el preciso análisis que lleva a cabo CEBRIÁN SALVAT, M.A., "Estrategia procesal y litigación internacional en la Unión Europea: distinción entre materia contractual y extracontractual”, Cuadernos de Derecho Transnacional, octubre 2014, Vol. 6, nº 2, págs. 318 y ss.

${ }^{12}$ Que permite demandar a una persona domiciliada en un Estado miembro ante el órgano jurisdiccional en el que se haya cumplido o deba cumplirse la obligación que sirve de base a la demanda.

${ }^{13}$ Como recuerda CEBRIÁN SALVAT, ibidem, pág. 322, el término español “cuasidelictual” no aporta nada distinto, pues es mera transcripción literal de la versión en inglés del Reglamento, en lugar de haberse efectuado una traducción ajustada a su sentido, como existe en la versión italiana donde, en lugar de materia delictual o cuasidelictual, se habla de ilícitos civiles dolosos o culposos, lo que en español hubiera facilitado la comprensión del precepto.

${ }^{14}$ Sin remitirse por tanto en su interpretación a un derecho nacional determinado, sino creando un concepto propio, en clave europea, de modo que se garantice su interpretación y aplicación uniforme por los tribunales de los distintos Estados miembros. Debe tenerse en cuenta que un mismo asunto puede recibir respuestas diferentes en los distintos Estados miembros, aplicando su derecho nacional. La intención del TJUE es que, al menos por lo que respecta a la calificación de la materia objeto de la acción, se 
ter v. Fabrication de montres normandes EURL y Karsten Fräbdorf) como materia extracontractual toda pretensión con la que se exija la responsabilidad de un demandado que ha cometido un hecho dañoso, con o sin dolo, y que no esté relacionada con la materia contractual, bien porque no exista un compromiso previo libremente asumido por las partes, bien porque, aunque exista, la acción que se ejercita no esté basada en dicho compromiso.

En definitiva, aunque exista un contrato entre las partes, la acción puede también calificarse como extracontractual. Para ello el tribunal al que le llega el asunto tendrá que analizar si la conducta imputada al demandado supone o no un incumplimiento de ese contrato, conforme al objeto del contrato y los hechos concretos que se enjuicien ${ }^{15}$. Así, si para resolver sobre la pretensión fuera indispensable tener en cuenta al contrato, es decir, si para valorar la licitud o ilicitud de la actuación del demandado a la vista de los hechos concretos es necesario tomar en consideración el contrato, aquella habrá de calificarse como contractual en el sentido del artículo 7.1 del Reglamento Bruselas I bis, siendo entonces foro competente la jurisdicción del lugar en el que se haya cumplido o deba cumplirse la obligación que sirva de base a la demanda; por ejemplo, en el caso de una prestación de servicios como la analizada en la citada STJUE de 13 de Marzo de 2014 (asunto C-548/12), el lugar del Estado miembro en el que, según el contrato, se hayan cumplido o hayan de cumplirse los servicios, salvo pacto en contrario.

Como se verá más adelante, la calificación como contractual o extracontractual de una materia a los efectos de determinar el foro no ha de condicionar necesariamente, aunque sí resulte recomendable, la calificación que se le otorgue a efectos de ley aplicable al fondo del litigio, de modo que, si contractual, el tribunal debiera de aplicar el Reglamento (CE) no 593/2008, de 17 de junio, sobre la ley aplicable a las obligaciones contractuales -Roma I-, para determinar la ley aplicable a la resolución del conflicto; y si se califica como extracontractual, sería el Reglamento (CE) no 864/2007, de 11 de julio, relativo a la ley aplicable a las obligaciones extracontractuales -Roma $I I-$ - el utilizado. En principio, esa calificación se habrá de hacer con arreglo a la ley del foro. Volveré sobre esto en la tercera parte de este trabajo, adelantando ya, sin embargo, que la doctrina ${ }^{16}$ ha revelado la existencia de una discordancia reseńable entre el artículo 7.2 del Reglamento Bruselas I bis y el artículo 9 del Reglamento Roma II, discordancia que puede llevar a la situación de que el tribunal competente para conocer de la cuestión litigiosa relativa a las acciones de conflicto colectivo (el del lugar donde se haya producido o pueda producirse el hecho dañoso) haya de aplicar a la acción de responsabilidad por daños la ley de otro Estado Miembro (la del país donde se realiza la acción de conflicto o donde vaya a producirse).

De la misma forma, aunque la impugnación de convenios colectivos en principio no esté expresamente incluida dentro del ámbito de aplicación de Bruselas I Bis, si la validez de un convenio colectivo y su cumplimiento o incumplimiento es una cuestión accesoria o accidental del pleito principal, quedaría incluida en el Reglamento, en este caso como materia contractual. Y es

parta del mismo concepto, para lo cual ha tenido que resolver numerosas cuestiones prejudiciales sobre la distinción entre materia contractual y extracontractual. Y en ellas se ha decantado por esa interpretación autónoma: por ejemplo, en la ya citada sentencia de 27 de septiembre de 1988, asunto Kalfelis Schroder, sostiene que "Como este Tribunal de Justicia juzgó a propósito del concepto de "materia contractual", empleado por el apartado 1 del artículo 5 (véanse las sentencias de 22 de marzo de 1983, Peters, 34/82, Rec. 1983, p. 987, y de 8 de marzo de 1988, PRL Arcado y SA Haviland, 9/87, Rec. 1988, p. 1539), teniendo en cuenta los objetivos y la sistemática general del Convenio, y, con el fin de asegurar en la medida de lo posible la igualdad y uniformidad de los derechos y obligaciones derivados del mismo para los Estados contratantes y las personas interesadas, es importante no interpretar dicho concepto como una simple remisión al Derecho interno de uno de los Estados afectados. Consiguientemente, hay que considerar el concepto de en materia de delitos o cuasidelitos como un concepto autónomo, que debe interpretarse, para la aplicación del Convenio, refiriéndose principalmente al sistema y a los objetivos de aquél, con el fin de asegurar su plena eficacia" (apartados 15 y 16).

${ }^{15}$ Véase esta idea en CEBRIÁN SALVAT, ibídem, pág. 329.

${ }^{16}$ PERARO, C., "Right to collective action in cross-border employment contexts: a fundamental social right not yet covered by EU private international law”, UNIO-EU Law Journal, Vol. 2, n 2, 2016, pág. 37. 
que, como ha sostenido la doctrina ${ }^{17}$, una vez firmado un convenio colectivo, los sujetos firmantes están inmersos en una relación "contractual". Es decir, el resultado de la negociación colectiva es un "contrato" en aplicación de la doctrina del TJUE, que mantiene una interpretación amplia y autónoma del concepto, incluyendo aquellas situaciones en que una parte voluntariamente asume obligaciones hacia otra parte.

En algunos países se establece, por lo demás, un deber de paz, relativo o absoluto, durante la vigencia del convenio colectivo, de manera que los conflictos colectivos que se produzcan afectando a ese deber de paz pueden ser considerados como una vulneración de una obligación "contractual" por el sujeto colectivo que los plantee. De este modo, la responsabilidad por el incumplimiento del deber de paz previsto en el convenio podría ser calificada como materia contractual, y no extracontractual, a los efectos de los foros especiales del artículo 7 del Reglamento Bruselas I bis.

En consecuencia, en estos casos, para determinar el órgano judicial competente para conocer del asunto, lo primero que habría que analizarse es si existe una sumisión tácita o expresa a un foro determinado (arts. 25 y 26 Bruselas I Bis). En su defecto, los demandantes pueden elegir entre interponer la demanda ante los tribunales del domicilio del demandado ${ }^{18}$ si este está domiciliado en un Estado Miembro (art. 4 Bruselas I Bis) o ante los tribunales a los que corresponda de acuerdo con el principio de proximidad al objeto del conflicto, esto es, los tribunales del lugar en el que se haya cumplido o deba cumplirse la obligación que sirve de base a la demanda (art. 7.1.a) Bruselas I Bis).

En fin, aun cuando se haya concluido que el Reglamento Bruselas I Bis no contiene reglas de conflicto expresas para determinar cuál es el órgano judicial competente para resolver conflictos referentes al ejercicio colectivo de derechos laborales colectivos y en los que exista elemento internacional o de extranjería, se ha de resaltar también que las normas de conflicto comunitarias sí resultan en cambio aplicables para determinar la competencia judicial en los litigios que surgen en relación al ejercicio individual de los derechos laborales colectivos y sus efectos sobre la relación individual de trabajo ${ }^{19}$, de modo que en estos casos se aplicarán, como sucede con el contrato individual de trabajo, en primer lugar, los foros voluntarios (de sumisión expresa o tácita) y, en su defecto, el foro general y los foros especiales, de aplicación alternativa ${ }^{20}$.

\subsection{La jurisdicción española competente en los conflictos en materia de relaciones colectivas de trabajo}

Como ya he anticipado, en los conflictos colectivos o vinculados con el ejercicio colectivo de los derechos colectivos de trabajo, en caso de que el Reglamento Bruselas I Bis no resulte aplicable, rigen las normas internas (nacionales) de derecho internacional privado para determinar la jurisdic-

\footnotetext{
${ }^{17}$ Véanse DORSSEMENT, F. y VAN HOEK, A., "Collective action in Labour conflicts under the Rome II Regulation (part I)”, European Labour Law Journal, Vol. 2, no 1, 2011, pág. 68; CARBALLO PINEEIRO, L., International Maritime Labour Law, Ed. Springer, 2015, págs. 257-258.

${ }^{18}$ Para saber cuál es el domicilio del demandado cuando estamos ante una persona jurídica se ha de acudir a lo previsto en el artículo 63 del Reglamento Bruselas I Bis.

${ }^{19}$ En la doctrina española puede verse esta opinión, por todos, en FOTINOPOULOU BASURKO, O., La determinación de la ley aplicable al contrato de trabajo internacional, Ed. Thomson-Aranzadi, 2006, págs. 71 y ss.; SERRANO GARCÍA, M.J., Competencia judicial y ley aplicable en el ámbito de los contratos de trabajo internacionales, Ed. Reus, Madrid, 2011, pág. 45; o CRESPO HERNÁNDEZ, A., Análisis metodológico de la ley aplicable a la responsabilidad por daños derivados de la adopción de medidas de conflicto colectivo. Disponible en: http://pendientedemigracion.ucm.es/info/kinesis/analisis-conflicto-colectivo.pdf, pág. 7. En la doctrina extranjera, DORSSEMENT, F. y VAN HOEK, A., "Collective action in Labour conflicts under the Rome II Regulation (part I)", cit., págs. 7172; o PERARO, "Right to collective action in cross-border employment contexts: a fundamental social right not yet covered by EU private international law”, cit., págs. 36-37.

${ }^{20}$ Véase TODOLÍ SIGNES, A., "La competencia judicial y la prueba de derecho extranjero en caso de movilidad internacional de trabajadores. Especial mención a la nueva ley de cooperación judicial internacional”, En: LÓPEZ TERRADA, E. (Dir.), La internacionalización de las relaciones laborales. Principales cuestiones procesales, laborales y fiscales, Ed. Tirant Lo Blanch, 2017, pág. 72 y ss.
} 
ción competente, también llamadas normas residuales; en nuestro caso ${ }^{21}$, concretamente, el artículo 25.2 de la LOPJ; el artículo 36 de la Ley 10/1997, de 24 de Abril, sobre derechos de información y consulta de los trabajadores en las empresas y grupos de empresas de dimensión comunitaria, modificada por Ley 44/1999, de 29 de Noviembre; y el artículo 34 de la Ley 31/2006, de 18 de Octubre, sobre implicación de los trabajadores en las sociedades anónimas y cooperativas europeas.

En los casos regidos por las dos últimas normas, que transponen Directivas comunitarias ${ }^{22}$, nos encontramos en presencia de derechos de titularidad y ejercicio colectivo, que han sido concebidos y reconocidos a los trabajadores como colectivo ${ }^{23}$. Ello puede apreciarse, de modo evidente, en los artículos que regulan la legitimación procesal, reconocida en ambas leyes únicamente a sujetos colectivos (arts. 37 de la Ley 10/1997 y 35 de la Ley 31/2006, refiriéndose a los empresarios, los representantes de los trabajadores, la comisión negociadora y el Comité de Empresa Europeo o el órgano de representación de los trabajadores de la Sociedad Europea, así como los sindicatos de trabajadores y las asociaciones empresariales), y no así al trabajador individual.

Así, serán competentes para conocer de conflictos relacionados con derechos colectivos laborales en relaciones de trabajo con elemento internacional:

a) Los Juzgados y Tribunales españoles del orden social, en materia de control de legalidad de los convenios colectivos celebrados en España y de pretensiones derivadas de conflictos colectivos de trabajo promovidos en territorio español (artículo 25.2 de la LOPJ).

A este respecto. el Tribunal Supremo ha señalado, en sentencia de 20 de julio de 2007 (Ro. 76/2006, Sala de lo Social), que, cuando el conflicto no es una confrontación colectiva en sentido estricto sino que afecta de forma directa a los contratos de trabajo y se sustancia de forma colectiva porque afecta a un grupo de trabajadores y se plantea de forma general, para aplicar el art. 25.2 LOPJ el conflicto colectivo habrá de tener un elemento de conexión con el territorio nacional, lo que se da si está presente alguno de los factores que recoge el artículo $25.1^{24}$, esto es, que los servicios se hayan prestado en Espańa o el contrato de trabajo se haya celebrado en territorio español; cuando el domicilio del demandado se ubique en Espańa o tenga aquí una sucursal, agencia o establecimiento ${ }^{25}$; cuando tanto trabajador como empresario posean nacionalidad española, cualquiera que sea el lugar de la prestación de servicios o de celebración del contrato; y en caso del contrato de embarque, si el contrato fue precedido de una oferta recibida en España por trabajador español ${ }^{26}$.

Por otro lado, nuestras normas procesales internas no atribuyen competencia específica a un órgano concreto para conocer de los conflictos colectivos que trascienden nuestras fronteras -cuyos efectos se extienden fuera de nuestras fronteras-, por lo que podrá ser competente un Juzgado de lo Social, el Tribunal Superior de Justicia o la Audiencia Nacional, que son los órganos a los que nuestra

${ }^{21}$ Resulta útil para comprender toda la dimensión de las normas residuales el cuadro comparativo incluido en CEBRIÁN SALVAT, M.A., "La competencia judicial internacional residual en materia contractual en España", Cuadernos de Derecho Transnacional, Vol. 9, no 2, 2017, págs. 134-135

${ }^{22}$ Directivas 2009/38/CE, de 6 de mayo de 2009, "sobre la constitución de un comité de empresa europeo o de un procedimiento de información y consulta a los trabajadores en las empresas y grupos de empresa de dimensión comunitaria”; y 2001/86/CE, de 8 de octubre de 2001 y 2003/72/CE, de 22 de julio de 2003, "sobre implicación de los trabajadores en las sociedades anónimas y cooperativas europeas".

${ }^{23}$ PONS CARMENA, M., La participación de los trabajadores en la empresa en el ámbito de la Unión Europea, Ed. Tirant Lo Blanch, 2016, p. 201

${ }^{24}$ Un análisis de tales factores en MENÉNDEZ SEBASTIÁN, "Competencia judicial en el contrato laboral con elemento extranjero", cit., págs. 100-104.

${ }^{25}$ Señala acertadamente TODOLÍ SIGNES, ob.cit., pág. 88, que en este último caso la norma aplicable sería el Reglamento Bruselas I bis, salvo que el conflicto no estuviera relacionado con dicho establecimiento.

${ }^{26}$ Véase al respecto, entre otras, la interesante sentencia del TSJ de Galicia, de 26 de abril de 2004 (Ro. 946/2004). 
legislación procesal atribuye la competencia en instancia. Sin embargo, cada uno de ellos la ostenta conforme al principio de territorialidad, esto es, en función del ámbito territorial del conflicto. El problema aquí es que el ámbito del conflicto excede de la solución aportada por nuestro ordenamiento.

Por este motivo, el Tribunal Supremo, en sentencia de 20 de abril de 2015 (Ro. 100/2014, Sala de lo Social), ha tenido que pronunciarse sobre este problema, al menos en un asunto planteado como conflicto colectivo donde la empresa es española, y la mayoría de trabajadores (900) tiene como lugar de trabajo una única Comunidad Autónoma (Extremadura), siendo 6 los trabajadores que ejercen su actividad en el extranjero. De este modo, en su Fundamento de Derecho Quinto sostiene que "Puesto que las normas orgánicas sobre competencia jurisdiccional no atribuyen de forma expresa la misma a ningún tribunal español en casos como el presente, lo lógico es neutralizar el elemento de internacionalidad que el ordenamiento ignora. De este modo, el juez natural de un conflicto con proyección internacional es el mismo que lo sería si los efectos se desplegasen solo dentro de las fronteras del Estado. En consecuencia: 1) Las normas procesales solo determinan la competencia judicial en función del ámbito territorial del conflicto colectivo dentro de las fronteras españolas. 2) La existencia de trabajadores destacados en otros paises comunitarios no puede alterar la competencia judicial. 3) No es equiparable la situación de la empresa que posee centros de trabajo en varias Comunidades Autónomas con la de aquella que solo está establecida en una Comunidad y tiene delegaciones internacionales". En definitiva, el juzgador en este tipo de conflictos con elemento de internacionalidad ha de ser el mismo que asumiría el asunto de no existir tal elemento; en el caso de autos, el Tribunal Superior de Justicia de Extremadura.

b) Los órganos jurisdiccionales españoles del orden social, en los litigios referidos a los derechos de información y consulta de los trabajadores en las empresas y grupos de empresa de dimensión comunitaria, cuando las partes se hayan sometido expresa o tácitamente a los mismos o, en su defecto, cuando el demandado tenga su domicilio en Espańa o cuando la obligación que sirviese de base a la demanda hubiese sido o debiese ser cumplida en territorio español (artículo 36.1 de la Ley 10/1997). La competencia de los órganos jurisdiccionales españoles del orden social se determinará de acuerdo con las reglas contenidas en los artículos 6 a 11 de la Ley 36/2011, de 10 de octubre, Reguladora de la Jurisdicción Social. Establece al respecto el artículo 36.2 Ley 10/1997 que, para determinar el órgano judicial competente, en los procesos de conflictos colectivos, sobre impugnación de convenios colectivos y sobre tutela de los derechos de libertad sindical se atenderá a la extensión de sus efectos en territorio español. En estos casos, en ausencia de acuerdo o de determinación expresa al respecto, el artículo 36.3 Ley 10/1997 dispone que se entenderá que el domicilio de la comisión negociadora y del comité de empresa europeo es el de la dirección central.

c) Los órganos jurisdiccionales españoles del orden social conocerán de los litigios que se planteen en aplicación de la Ley 31/2006, cuando las partes se hayan sometido expresa o tácitamente a los mismos o, en su defecto, el demandado tenga su domicilio en Espańa o cuando la obligación que sirviese de base a la demanda hubiese sido o debiese ser cumplida en territorio español (artículo 34.1 de la Ley 31/2006). A la hora de determinar el órgano judicial competente para conocer un proceso de conflicto colectivo, sobre impugnación de convenios colectivos y sobre tutela de los derechos de libertad sindical producidos en el ámbito de esta Ley se atenderá, aquí también, a la extensión de sus efectos en territorio espańol, como señala el artículo 34.2 Ley 31/2006. Igualmente, en estos casos, en ausencia de acuerdo o de determinación expresa al respecto, se entenderá que el domicilio de la comisión negociadora y del órgano de representación es el de registro de la Sociedad Europea, conforme al artículo 34.3 Ley 31/2006. 


\section{Determinación de la ley aplicable en materia laboral colectiva}

\subsection{Las normas aplicables en función del ejercicio individual o colectivo de los derechos colectivos labo- rales: ¿Reglamento (CE) no 593/2008 -ROMA I- y/o Reglamento (CE) no 864/2007 -ROMA II-?}

A la hora de analizar las fuentes comunitarias reguladoras de la determinación de la ley aplicable en los conflictos que afecten al ejercicio extraterritorial de los derechos colectivos laborales en relaciones con elemento internacional o de extranjería, necesariamente se ha de distinguir entre el ejercicio individual (a) o colectivo (b) de los mismos.

3.1. a) Así, como ya hemos adelantado, las normas de conflicto comunitarias, cuando se dan las circunstancias en ellas exigidas, resultan plenamente aplicables a los litigios que surgen en relación al ejercicio individual de los derechos laborales colectivos y a sus consecuencias sobre la relación individual de trabajo, tanto a efectos de competencia judicial internacional (Reglamento Bruselas I Bis complementado por Convenio de Lugano II) -ya visto antes brevemente- como de determinación de ley aplicable (por aplicación del Reglamento (CE) no 593/2008, de 17 de junio de 2008, sobre la ley aplicable a las relaciones contractuales -conocido como Roma I-, que sustituyó al Convenio de Roma de 19 de junio de 1980; y/o por aplicación de la Directiva 96/71/CE).

Concretamente, por lo que respecta a la ley aplicable, la solución de los conflictos de leyes generados en relaciones de trabajo con elemento internacional, por ejemplo, por la existencia de conductas discriminatorias relacionadas con el ejercicio individual del derecho de libertad sindical o con el ejercicio de las funciones representativas, por la aplicación o inaplicación al trabajador del contenido de un acuerdo/convenio colectivo determinado, o por la participación del trabajador individual en una huelga o cualquier acción colectiva sometida al Derecho internacional privado que repercuta de forma negativa en su relación individual de trabajo, provocando por ejemplo su despido, o un descuento arbitrario sobre su retribución, vendrá dada por la aplicación del ordenamiento jurídico al que remitan los criterios de conexión del artículo 8 del Reglamento Roma ${ }^{27}$, y por las leyes de policía y/o la excepción de orden público del país del foro y del país de ejecución del contrato de trabajo conforme a lo previsto en los artículos 9 y 21 del mismo Reglamento.

Ejemplos del uso de estos criterios de conexión en litigios donde se dirimen cuestiones relativas al ejercicio individual de derechos laborales colectivos pueden encontrarse, en nuestra jurisprudencia, en las sentencias del Tribunal Supremo de 26 de octubre y de 27 de noviembre de 1982, sobre consecuencias de la participación en huelga prohibida según las normas de orden público aplicables en el lugar de trabajo ${ }^{28}$; y de 16 de febrero de 1994 (Ro. 351/1993, Sala de lo Social) y de 7 de julio de 1997 (Ro. 206/1997, Sala de lo Social), sobre ámbito de aplicación de convenio colectivo en relación de trabajo internacional.

Pero también pueden encontrarse sentencias de Tribunales Superiores de Justicia en las que se despeja cuál haya de ser la ley aplicable en supuestos de ejercicio individual de derechos colectivos con repercusión en el contrato de trabajo. Por ejemplo, del TSJ de Madrid pueden citarse las sentencias de 17 de diciembre de 2007 ( $\mathrm{R}^{\mathrm{o}}$. 4382/2007), sobre convocatoria de huelga que provoca el despido del trabajador, considerado nulo como consecuencia de la aplicación del derecho griego; o de 17 de

\footnotetext{
${ }^{27}$ De forma resumida, pues es abundante la doctrina que ha estudiado este aspecto de la cuestión y no es la materia propia de este trabajo, la ley que gobierne el caso concreto vendrá dada por la aplicación alternativa de los criterios de electio iuris, lex loci laboris, lex loci celebrationis y, finalmente, los vínculos más estrechos.

${ }^{28}$ Una nota crítica a la aplicación de las leyes de policía extranjeras en estos casos, por incompatibles con los principios del orden público español, puede verse en GARDEÑES SANTIAGO, M., "Derecho imperativo y contrato internacional de trabajo", Revista del Ministerio de Empleo y Seguridad Social, no 132, 2017, pág. 173.
} 
noviembre de 2014 (Ro. 609/2014), sobre lesión del derecho de libertad sindical de trabajador sujeto de una relación de trabajo con elemento internacional. También resulta especialmente interesante la sentencia del TSJ de Galicia, de 26 de abril de 2004 (Ro. 946/2004), donde se establece que la calificación, validez y eficacia de acuerdos colectivos extranjeros ha de hacerse conforme a la legislación aplicable al acuerdo, la extranjera, y no conforme a la legislación española, aunque, en todo caso, en su aplicación a la relación individual de trabajo habrán de respetarse las normas de orden público del foro, lo que lleva a considerar nula una cláusula del citado acuerdo, por contraria al principio de no discriminación por razón de la edad existente en el ordenamiento jurídico español.

3.1.b) Sin embargo, el Reglamento Roma I no contiene reglas de conflicto de leyes aplicables al ejercicio colectivo de los derechos colectivos laborales ${ }^{29}$, quizás porque no son tan numerosos los supuestos conflictivos vinculados con más de un ordenamiento jurídico, a diferencia de lo que ocurre con los que afectan a la relación individual de trabajo.

De modo similar a como sucede con las cuestiones de competencia judicial, las cuestiones conflictivas relativas a la determinación de la ley aplicable al régimen jurídico sindical (constitución de sindicatos y organizaciones empresariales, capacidad de obrar, funcionamiento interno, responsabilidad civil o penal y hasta patrimonial); a los requisitos para el establecimiento de sistemas de participación o representación de los trabajadores en la empresa y a su funcionamiento (competencias, garantías, facilidades de actuación etc.); a los requisitos para la negociación y aplicación de convenios colectivos, a su validez y eficacia; o a las condiciones de ejercicio del derecho de huelga u otras medidas de conflicto colectivo y sus consecuencias, no se encuentran contempladas dentro del ámbito de aplicación del Reglamento Roma I, de modo que los criterios de conexión previstos en este Reglamento no les resultan aplicables ${ }^{30}$.

Por este motivo, cuando se plantea la cuestión relativa a cuáles puedan ser los criterios de conexión a utilizar para resolver el problema de determinación de la ley aplicable que pueda afectar a tales derechos no resulta sencillo dar una respuesta inequívoca o irrefutable, pues son muchos los interrogantes que hay que enfrentar. En este trabajo se proponen algunas respuestas, aunque no puedan considerarse concluyentes. De este modo:

10) Comenzando con el derecho de libertad sindical, las cuestiones litigiosas pertenecientes al derecho de sociedades, asociaciones y otras personas jurídicas (que afecten por tanto, en lo que aquí interesa, a organizaciones sindicales o empresariales) relativas a materias como la constitución, la capacidad jurídica, el funcionamiento interno, la disolución, el régimen de responsabilidades, etc., se encuentran expresamente excluidas del ámbito de aplicación del Reglamento Roma I en su artículo 1.2.f) ${ }^{31}$.

Si se trae en este punto, a falta de norma de conflicto aplicable, la jurisprudencia del TJUE en materia de sociedades, puede destacarse la doctrina siguiente ${ }^{32}:$ (1) en primer lugar, que las sociedades

\footnotetext{
${ }^{29}$ Lo explica muy claramente LABORDE, J.P., "Les rapports collectifs de travail en droit internationale privé ", Droit international privé : travaux du Comité français de droit international privé, 13e année, 1995-1998. 2000, pág. 173, cuando dice que "La convention de Rome n'a pas entendu s'appliquer aux conventions collectives : l'article 6 précise bien que c'est le contrat individuel de travail et que la loi de ce contrat englobe les conventions collectives, donc, sur ce point-là c'est très clair. Mais, il n'y a pas de dispositions et elle n'entend pas s'appliquer au rapport collectif de travail».

${ }^{30}$ En el mismo sentido, FOTINOPOULOU BASURKO, La determinación de la ley aplicable al contrato de trabajo internacional, cit., p. 74.

${ }^{31}$ Sostiene la doctrina sobre esta exclusión que "es indudable que el Reglamento debe ser compatible, en este punto, con las propias normas comunitarias relativas a la politica de sociedades, y que este sector del ordenamiento tiene una dimensión institucional que escapa razonablemente de un régimen de obligaciones contractuales". Cfr. FERNÁNDEZ ROZAS y SÁNCHEZ LORENZO, Derecho internacional privado, cit., pág. 446. Sin embargo, en el caso que nos ocupa no resulta aplicable el derecho europeo societario, más específico.

${ }^{32}$ En extenso, GARCIMARTÍN, F., (2015), "De nuevo sobre la ley aplicable a las sociedades en Europa: ¿̨hacia un futuro
} 
son "creaciones" del Derecho nacional, por lo que solo existen en la medida en que hayan sido "creadas" al amparo del Derecho de un Estado miembro 33 ; (2) y en segundo lugar, cada Estado establece las condiciones para que una sociedad pueda constituirse bajo su propio ordenamiento y, en particular, el punto de conexión que la vincula con el mismo ordenamiento y la hace, en ese caso, titular de la libertad de establecimiento ${ }^{34}$, sea el domicilio estatutario o la sede de su administración efectiva.

En consecuencia, a esas cuestiones resultará aplicable el derecho nacional, de modo que la ley personal de estas asociaciones, que podrá ser la determinada por su nacionalidad, será la que deba aplicarse en cuestiones litigiosas relativas a esta materia, sin perjuicio de la posible aplicación de las leyes de policía de otros ordenamientos jurídicos. Concretamente, en nuestro caso, dispone el artículo 9.11 del Código Civil que "la ley personal correspondiente a las personas jurídicas es la determinada por su nacionalidad, y regirá en todo lo relativo a capacidad, constitución, representación, funcionamiento, transformación, disolución y extinción. En la fusión de sociedades de distinta nacionalidad se tendrán en cuenta las respectivas leyes personales". Por lo que se refiere a las organizaciones sindicales conforme al derecho nacional, son la Ley Orgánica 11/1985, de 1 de agosto, de Libertad Sindical (LOLS) y resto de normas del ordenamiento laboral donde se regula todo lo relativo a su constitución, capacidad, etc., disponiendo el artículo 4 LOLS que dichas organizaciones adquieren personalidad jurídica y plena capacidad de obrar a los 20 días hábiles del depósito de sus estatutos en la oficina pública correspondiente a su ámbito territorial de actuación.

Por su parte, los derechos y obligaciones de las organizaciones sindicales hacia sus afiliados y viceversa, esto es, los conflictos que puedan surgir entre un sindicato y sus afiliados, trabajen estos últimos donde trabajen e incluyendo por tanto la obligación de prestarles servicios y apoyo cuando trabajan en el extranjero ${ }^{35}$, se encuentran igualmente sometidos a la ley que se aplica al sindicato.

En realidad, si los sindicatos están sujetos a la ley del país de su creación, que generalmente determina su capacidad para representar a los trabajadores en un territorio específico, que habitualmente coincide con el ámbito territorial y funcional de actuación de la organización prevista en sus normas internas (Estatutos o reglamentos de actuación), hemos de ser conscientes de que las actividades sindicales transnacionales, o allende las fronteras del territorio en el que estas organizaciones se han creado, están limitadas por ese principio de territorialidad. Por ello, son en realidad las organizaciones internacionales de trabajadores las que, en ocasiones de forma conjunta con organizaciones sindicales nacionales, y en otras de forma aislada, llaman a la realización de acciones de conflicto colectivo de carácter transnacional o negocian acuerdos marco globales o internacionales (AMI) con las empresas multinacionales, consideradas como un espacio claro de acción para las organizaciones sindicales, respecto no sólo de las relaciones laborales en los centros que éstas poseen en terceros países (esto es, la compañía matriz y sus entidades locales o filiales) sino, principalmente, en las empresas integrantes de la conocida como cadena de suministro o cadena global de producción (proveedores y subcontratistas), presentes también en terceros países en los que la normativa protectora de los derechos de los trabajadores es escasa o, sencillamente, inexistente, y donde la acción sindical encuentra todo tipo de obstáculos. La aplicación o no de las normas de conflicto comunitarias a estos acuerdos marco internacionales ha sido objeto de estudio de la doctrina internacional

\footnotetext{
reglamento?”. Disponible en: https://almacendederecho.org/de-nuevo-sobre-la-ley-aplicable-a-las-sociedades-en-europa-hacia-unfuturo-reglamento/ (visto el 7 de junio de 2019).

33 "Las sociedades son creación del Derecho y, en el estado presente del Derecho europeo, creaciones del Derecho nacional. Sólo existen en virtud de las diversas leyes nacionales que determinan su constitución y funcionamiento" (asuntos C-81/87, Daily Mail, ap. 19; C-208/00, Uberseering, ap. 67; C-210/06, Cartesio, ap. 104; C-378/10, Vale Epitesi, ap. 27)

34 “.... un Estado miembro... tiene el poder incuestionable para definir el punto de conexión requerido para que esa sociedad sea considerada como válidamente constituida de acuerdo con su Derecho y, como tal, sujeto de la libertad de establecimiento y el factor de conexión requerido para que la sociedad pueda mantener, subsiguientemente, tal status" (asunto C-378/10, Vale Epitesi, ap. 29).

${ }^{35}$ Esta idea puede verse en CARBALLO PIÑEIRO, International Maritime Labour Law, cit., pág. 233.
} 
privatista $^{36}$, que no ha llegado a conclusiones indiscutibles al respecto. Más concluyente resulta, sin embargo, la escasa doctrina laboralista que se ha pronunciado sobre el tema ${ }^{37}$.

20) Para resolver los litigios sobre representación de los trabajadores en las empresas (elección o designación, funciones representativas, competencias, derechos y garantías, etc.) cuando existe un elemento de extranjería (normalmente, trabajador de un país prestando servicios en una empresa de un país diferente, y en donde surge la duda respecto de los derechos que le asisten en materia de representación), ha de partirse del hecho indudable de que cada Estado puede y suele regular esta cuestión de manera diversa, contemplándola desde una lógica interna. Además, debe tenerse presente que la materia ha sido objeto de distintas Directivas comunitarias con ánimo de armonizar su tratamiento en los distintos países de la Unión Europea ${ }^{38}$.

Normalmente, a estas cuestiones litigiosas les ha sido aplicada la ley seleccionada con base en el principio de territorialidad ${ }^{39}$, esto es, la ley del lugar en el que se van a ejercitar estos derechos; en otras palabras, la ley aplicable en el centro de trabajo. Pero esta aplicación se produce porque, como la doctrina ha expresado recientemente a la luz de la jurisprudencia francesa en la materia ${ }^{40}$, en el ámbito del derecho internacional privado, la normativa estatal sobre representación de los trabajadores se considera como ley de policía, que se impone a toda empresa que desarrolle su actividad con trabajadores contratados en su territorio ${ }^{41}$, independientemente de dónde la empresa tenga su sede, lo que incluso podría dar lugar a la existencia de una doble representación si tales trabajadores contaran con los órganos de representación previstos en la legislación aplicable al Estado donde la empresa tenga su sede.

Un ejemplo de esta situación se observa en la decisión de la Cour de Cassation francesa, de 14 de enero de 2004 ( $\mathrm{n}^{\circ}$ de recurso 02-60119), resolviendo la demanda sobre el derecho a organizar elecciones a delegados de personal planteada entonces por los trabajadores de una empresa holandesa contratados en Francia para prestar servicios en este país, en la que el tribunal establece que "Mais attendu, d'abord, que le juge du fond ayant souverainement constaté que les salariés employés par la société AGIO en permanence sur le territoire français ne bénéficient d'aucune représentation du personnel sur ce territoire pour l'exercice de leurs droits collectifs et la sauvegarde des intérêts spécifiques défendus par les

${ }^{36}$ Por citar alguno reciente, véanse VAN HOEK, A.A.H., "Finding a legal framework for transnational collective agreements through international private law", Amsterdam Law School Legal Studies Research Paper, Centre for the Study of European Contract Law, 2016-02; SALÉS PALLARES, L. y MARULLO, M.C., "El ángulo muerto del derecho internacional: las empresas transnacionales y sus cadenas de suministro", Persona y Derecho, Vol. 78, 2018, págs. 261-291.

${ }^{37}$ FOTINOPOULOU BASURKO, O., "Las relaciones colectivas de trabajo en el Derecho Internacional Privado", Revista del Ministerio de Empleo y Seguridad Social, no 132, 2017.

${ }^{38}$ Deben, en todo caso, respetarse las Directivas 2009/38/CE, de 6 de Mayo de 2009, "sobre la constitución de un comité de empresa europeo o de un procedimiento de información y consulta a los trabajadores en las empresas y grupos de empresa de dimensión comunitaria"; 2001/86/CE, de 8 de Octubre de 2001 y 2003/72/CE, de 22 de Julio de 2003, "sobre implicación de los trabajadores en las sociedades anónimas y cooperativas europeas"; y 2002/14/CE, de 11 de Marzo de 2002, "por la que se establece un marco general relativo a la información y a la consulta a los trabajadores en la Comunidad Europea”, aplicable en empresas o centros de trabajo localizados en Europa que tengan una dimensión determinada. Disponen todas ellas, con carácter general, que es competencia de los Estados miembros determinar a través de las normas nacionales de transposición los mecanismos adecuados para garantizar su cumplimiento, obligando a estas normas a tutelar la aplicación de los derechos participativos más allá de sus fronteras (por ejemplo, se contempla en ellas la posibilidad de responsabilizar a una dirección central o empresarial, o a un órgano competente de la Sociedad Anónima europea, y a sus trabajadores o a los representantes, estén situados o no en su territorio nacional).

${ }^{39}$ Con cita de jurisprudencia alemana, véase CARBALLO, International Maritime Labour Law, cit., pág. 303.

${ }^{40}$ Véanse LABORDE, "Les rapports collectifs de travail en droit internationale privé », cit., págs. 156 y ss.; FITA ORTEGA, F., "El impacto del actual contexto productivo en los derechos de representación de los trabajadores", Revista General de Derecho del Trabajo y Seguridad Social, no 46, 2017, pág. 124.

${ }^{41}$ La Cour de Cassation, civile, Chambre sociale, 14 février 2001, 99-60.355, mantuvo que «Toute personne juridique ayant son siège à l'étranger, qui, pour exercer son activité emploie des salariés sur le territoire français, exerce les responsabilités de l'employeur selon la loi française, et doit appliquer les lois relatives à la représentation des personnels dans l'entreprise ou l'organisme, au sens de l'article $L$. 421-1 du Code du travail" ". 
délégués du personnel, il en résulte que l'application immédiate de la loi française donnant le droit à ces salariés d'être représentés par des délégués du personnel au niveau le plus approprié permet d'apporter une solution au litige qui a pour seul objet la demande d'organisation d'élections à cette fin, de sorte qu'il n'y a pas lieu à renvoi préjudiciel». En otras palabras, constatado que los trabajadores contratados por la sociedad holandesa para trabajar en territorio francés no disponían de representantes para el ejercicio de sus derechos colectivos y la defensa de sus intereses específicos, aplicarles la legislación francesa dándoles derecho a estar representados por delegados de personal permite resolver un litigio que tiene por único objeto la demanda de organización de elecciones con esta finalidad. Y esta solución se dio por el tribunal aun cuando la empresa holandesa alegaba no tener establecimiento acreditado ni estructura alguna en el país de acogida, Francia, lo que la propia Corte desmiente con el siguiente argumento, aplicando la legislación francesa vigente en aquel momento y la noción de colectividad de trabajo con intereses comunes: "Attendu, ensuite, que le jugement attaqué, après avoir relevé que la société AGIO, qui dispose d'une organisation économique implantée sur le territoire français, exerce les responsabilités de l'employeur sur une collectivité de travail formée sur ledit territoire par plus de 10 salariés en présence d'un directeur et ayant des intérêts communs, a exactement décidé qu'il existait un établissement au sens de l'article L. 421-1 du Code du travail et que l'employeur devait organiser les élections des délégués du personnel; que le moyen n'est pas fondé». En definitiva, aplicando el Código de Trabajo francés vigente entonces ${ }^{42}$, la Cour de Cassation entendió, con el claro precedente de la decisión de 14 de febrero de 2001 ( $n^{\circ}$ de recurso 99-60355), que la empresa holandesa disponía de una organización económica en territorio francés y ejercía la responsabilidad como empleador sobre una colectividad conformada por más de 10 trabajadores dependientes de un director y con intereses comunes, lo que obligó a la empresa a acceder a la solicitud de organización de elecciones a delegados de personal.

En nuestra jurisdicción, con relación a las competencias de los representantes de los trabajadores y vinculada a la lex contractus, puede traerse a colación la opinión del Tribunal Supremo, expresada en sentencia de 7 de julio de 1997, en la cual, sin entrar a valorar si la norma de conflicto aplicable es el artículo 10.6 del Código Civil o son los artículos 3 y 6.1 del Convenio de Roma de 1980, precedente del Reglamento Roma I y aplicable entonces, señala que, en la medida en que los trabajadores de la empresa española -de nacionalidad austríaca y contratados en Austria para prestar servicios en aeronaves que cubren la ruta de Austria a las islas griegas- no estaban representados por la representación legal española a los efectos de la negociación colectiva, tampoco lo estaban a los efectos de entregarles la copia básica del contrato suscrito con aquellos y no sujeto, con carácter principal, a la legislación española.

3o) En los litigios sobre impugnación de los convenios colectivos -acaecidos principalmente, en ámbito transnacional, como consecuencia de la suscripción del convenio tras recurrir los sindicatos al uso de medidas de presión y conflicto colectivo como huelgas, boicots, acciones de solidaridad etc.- pero también en los de interpretación y aplicación de un convenio en una relación individual de trabajo con elemento de extranjería, es necesario, primeramente, determinar la ley aplicable a su existencia, su eficacia, la validez de su firma y su ámbito de aplicación, si lo que se quiere es precisamente cuestionar este tipo de materias.

En la búsqueda de una regla de conflicto de la que valerse al respecto, son diversas las opiniones y propuestas doctrinales ${ }^{43}$. De este modo, se ha sostenido que les será de aplicación la ley del país donde más contratos de trabajo haya sometidos al ámbito de aplicación del convenio colectivo,

\footnotetext{
${ }^{42}$ Sobre la reforma más reciente del Código del Trabajo puede verse JEAMMEAUD, A., "La reforma Macron del Código del Trabajo francés", Temas Laborales, no 139, 2017, págs. 13-54.

${ }^{43}$ Véase FOTINOPOULOU BASURKO, La determinación de la ley aplicable al contrato de trabajo internacional, cit., pág. 69, y las citas de otros autores que incluye en su texto.
} 
o donde se ejecuten la mayor parte de las relaciones de trabajo cubiertas por el convenio. Otros consideran más oportuno dejar a los sujetos negociadores la determinación de la ley reguladora del convenio colectivo, aplicable en caso de conflicto de leyes.

En realidad, la existencia de distintas propuestas doctrinales no es tan extraña como en principio pudiera estimarse, sino un resultado previsible de la posible norma de conflicto a aplicar. Y es que a este tipo de litigios les resulta de aplicación el Reglamento Roma I ${ }^{44}$, de modo que, en primer lugar, habrá que estar, según el artículo 3.1, a la autonomía de las partes como regla de conflicto (en este sentido, los convenios pueden incluir una cláusula sobre legislación aplicable, aunque lo habitual es que la elección sea tácita). En la práctica, seńala la doctrina ${ }^{45}$ que las partes tienden a aplicar la ley más próxima al convenio colectivo, ya que, de no hacerlo así y remitirse a un ordenamiento extranjero, el artículo 3.3 del Reglamento Roma I introduce límites a su autonomía, puesto que todos los mandatos imperativos de derecho colectivo vigentes en el Estado al que se refieren todos los elementos del caso -salvo la ley a la que se someten- resultan aplicables ${ }^{46}$.

En ausencia de elección, la ley aplicable conforme al artículo 4.2 Roma I sería la ley del país donde tenga su residencia habitual la parte que deba realizar la prestación característica del contrato. En otras palabras, resultaría aplicable la ley del lugar donde reside habitualmente la parte obligada a la prestación característica del convenio colectivo. Sin embargo, dado que aquí estamos hablando de litigios relativos a la aplicación y/o impugnación de un convenio colectivo, donde la prestación característica del contrato es compleja, el artículo 4.2 no puede aplicarse de forma literal. En consecuencia, la doctrina ha considerado que en este caso hay que recurrir a la ley del país con el que el convenio tiene un vínculo más estrecho ${ }^{47}$, aplicando el artículo 4.4 Roma I en lugar del artículo 4.2. Y es en la identificación de los posibles factores de conexión entre convenio y país donde surgen las propuestas a las que antes se hizo mención, así como muchas otras (por ejemplo, el ámbito territorial del convenio; la nacionalidad y residencia habitual de las partes; el lenguaje utilizado; la ley del lugar donde las obligaciones reguladas por el convenio vayan a llevarse a cabo, etc. ${ }^{48}$.

Será el juzgador quien, en función de estos criterios de conexión, determine la ley aplicable al convenio colectivo ${ }^{49}$, que regirá en consecuencia, conforme disponen los artículos 10 a 12 del Reglamento Roma I, su existencia, validez, eficacia, interpretación, el cumplimiento de las obligaciones que genere, las consecuencias de su incumplimiento y de su nulidad, o los modos de extinción de sus obligaciones.

Ahora bien, como límite se prevé la preceptiva aplicación de las leyes de policía, entendiendo

${ }^{44} \mathrm{Si}$ bien se refieren al acuerdo marco internacional y no exactamente al convenio colectivo, puede verse VAN HOEK, A. y HENDRICKX, F. (Coord.), International private law aspects and dispute settlement related to transnational company Agreements, 2009, pág. 9, donde dicen: "The distinction between contractual and non-contractual liability determines the application of Article 5(1) as opposed to Article 5(3) of the Brussels I Regulation as well as the respective scopes of application of the Rome I and Rome II Regulations. According to the ECJ, the concept of 'contractual matters' refers to obligations taken on voluntarily by one party towards another. The obligations do not have to qualify as contractual under national law. The concept is a relatively wide one. We conclude from this that the commitments of an employer as laid down in a TCA may come within the concept of contract when the commitments are claimed to be legally binding and specific enough as to their scope and content"

${ }^{45}$ CARBALLO PINÉEIRO, International Maritime Labour Law, cit., pág. 261.

46 "Cuando todos los demás elementos pertinentes de la situación estén localizados en el momento de la elección en un país distinto de aquel cuya ley se elige, la elección de las partes no impedirá la aplicación de las disposiciones de la ley de ese otro país que no puedan excluirse mediante acuerdo".

${ }^{47}$ En este sentido, CARBALLO PIÑEIRO, International Maritime Labour Law, cit., págs. 259 y 262; también FOTINOPOULOU BASURKO, "Las relaciones colectivas de trabajo en el Derecho Internacional Privado", cit., pág. 226.

${ }^{48}$ Véase CARBALLO, International Maritime Labour Law, cit., pág. 262.

${ }^{49}$ Resulta interesante aquí la sentencia del Tribunal Superior de Justicia de Galicia de 26 de abril de 2004 (Rec. Supl. 946/2004), cuando dice que "los acuerdos de 15.11.1993 y de 25.2.2003 no son calificables como acuerdos sobre materias concretas, ni en la cuestión de su validez y eficacia es trascendente su carácter estatutario o extraestatutario, simplemente porque esas calificaciones son propias de la legislación española, que en este aspecto resulta inaplicable -si lo fuese, se llegaría al absurdo que cualquier acuerdo colectivo extranjero, válido y eficaz conforme al derecho extranjero, sería tratado como extraestatutario en España-". 
por tales, conforme al artículo 9 del Reglamento Roma I, las disposiciones cuya observancia un país considera esencial para la salvaguardia de sus intereses públicos, hasta el punto de exigir su aplicación a toda situación comprendida dentro de su ámbito de aplicación, cualquiera que fuese la ley aplicable. Se refiere el legislador comunitario a las pertenecientes al derecho del Estado cuyos tribunales conocen del asunto, así como del Estado donde se ejecuta el contrato.

A este respecto, destaca en nuestra jurisdicción la sentencia del TSJ de Galicia, de 26 de abril de 2004 (Ro. 946/2004), en la que la Sala, debido a "la integración de los derechos fundamentales dentro del orden público español", reconoce que no puede dejar de aplicar las disposiciones imperativas españolas relativas a la discriminación por razón de edad, lo que le lleva a declarar nula conforme al derecho espańol vigente una cláusula del acuerdo colectivo extranjero aplicable a la relación de trabajo "al ser contraria a la prohibición de discriminación por razón de edad avanzada y, en consecuencia, el no llamamiento del demandante, avalado en esa cláusula, no puede considerarse amparado en causa justa de extinción del contrato de trabajo...".

Y es que, evidentemente, los Tribunales nacionales sí que pueden conocer, en los litigios sobre contratos individuales de trabajo, de la validez o eficacia de un convenio colectivo extranjero, de acuerdo con las leyes que lo regulen. Pero ese convenio colectivo habrá de respetar las leyes de policía del foro y del Estado en donde se ejecuta el contrato de trabajo, contrato que está regido no sólo por las normas legales y reglamentarias sino también, en su caso, por los convenios colectivos vigentes en el sistema de fuentes del ordenamiento jurídico que resulte aplicable a dicho contrato de acuerdo con lo previsto en el artículo 8 del Reglamento Roma $5^{50}$.

Para finalizar este apartado, debo seńalar que, aunque en algún ordenamiento se ha admitido la posibilidad de que el convenio goce directamente de una aplicación extraterritorial, sobre todo en el caso de trabajadores desplazados con derecho a retornar, siempre que existan suficientes vínculos con el país de origen del convenio y con la empresa ubicada alli ${ }^{51}$, lo habitual es que ello se vincule con la ley aplicable al contrato de trabajo, de manera tal que se admite la aplicación del convenio a relaciones laborales fuera del territorio para el que fue negociado, pero por el hecho de que tales contratos de trabajo están sometidos a la legislación del citado territorio. Y lo contrario: no se admite la inclusión dentro del ámbito de aplicación del convenio de tales relaciones de trabajo porque a ellas se aplica legislación extranjera ${ }^{52}$.

$4^{\mathbf{0}}$ En los litigios planteados a partir de la realización de una huelga internacional o la adopción de otras medidas de conflicto colectivo, son varios los temas a tratar. El primero es la cuestión de la ley aplicable a la calificación de la licitud de la huelga u otras medidas de conflicto colectivo, que debe diferenciarse de la determinación de aquella aplicable a sus consecuencias.

En la primera de las cuestiones -cuál es la ley aplicable a la determinación de la licitud o ilicitud de la huelga-, no existe regla conflictual alguna en el ámbito comunitario. Pero es ciertamente un aspecto esencial en estos conflictos, por las consecuencias que tal calificación tiene sobre los contratos individuales de trabajo y sobre la posibilidad de reclamar compensación por los dańos que eventualmente pudieran producirse. Lo cierto es que la cuestión de la licitud o ilicitud de la acción no es algo que se plantee en abstracto, sino que normalmente viene vinculado a una demanda planteada por los efectos que la participación en tal acción produce sobre el contrato de trabajo, o

\footnotetext{
${ }^{50}$ Por todos, LABORDE, "Les rapports collectifs de travail en droit internationale privé ", cit., pág. 159, donde señala que «En droit international privé tout au contraire, la loi compétente est en réalité l'ordre juridique compétent».

${ }^{51}$ En este sentido, CARBALLO PIÑEIRO, International Maritime Labour Law, cit., pág. 253, citando jurisprudencia alemana al respecto.

${ }^{52}$ Esta idea puede extraerse de la ya citada sentencia del Tribunal Supremo de 7 de julio de 1997 (Rec. Cas. 206/1997).
} 
de reclamación por daños, en supuestos, como la doctrina ha apuntado ${ }^{53}$, en los que existe divergencia entre la ley que regula los contratos de trabajo -la del Estado de origen- y la normativa que rige el conflicto colectivo en el país donde se encuentran los trabajadores. En otras palabras, suele tratarse de una cuestión incidental o accesoria al pleito principal.

Son muchos los partidarios de la aplicación de la ley del lugar donde se desarrolla la huelga (locus actus o lex loci actus) $^{54}$, lugar donde la normativa en materia de huelga suele tener reconocida la naturaleza de las normas imperativas absolutas o de orden público ${ }^{55}$, y que normalmente coincide con el lugar en el que los trabajadores que la secundan prestan servicios, aunque el empresario contra el que se dirige la acción no esté domiciliado en el mismo, y que se corresponde a su vez con el foro al que compete conforme a la norma de conflicto sobre competencia judicial aplicable a la responsabilidad por los daños causados (artículo 7.2 Reglamento Bruselas I bis), dada su calificación como materia delictual o cuasidelictual.

Respecto de la segunda cuestión -la determinación de la ley aplicable a las consecuencias de la huelga-, hay que distinguir, a su vez, entre, por un lado, (a) la cuestión relativa a la ley aplicable a los efectos que tal acción produce sobre el contrato de trabajo de los huelguistas (Roma I) y, por otro, (b) la relativa a la ley aplicable a la responsabilidad derivada de los daños provocados durante y por causa de la misma (Roma II).

(a) La primera cuestión, ya resuelta supra mediante la aplicación de las reglas de conflicto del Reglamento Roma I, plantea a su vez el problema de qué sucede cuando la ley aplicable que determina la ilicitud de la huelga -ley del lugar donde se desarrolla la acción- no coincide con la ley que se aplica al contrato individual de trabajo, respecto de los efectos que sobre el mismo produce la participación del trabajador en la huelga declarada ilícita conforme a la ley aplicable. Pudiera ser que, de acuerdo con el ordenamiento aplicable al contrato, dicha huelga hubiera sido calificada como lícita, de modo que los efectos sobre el contrato debieran ser otros.

Sobre esta cuestión lo cierto es que existen pronunciamientos antiguos de tribunales franceses, con los que la doctrina ha sido muy crítica $^{56}$, en los que, por ejemplo ${ }^{57}$, el despido del trabajador se declara procedente al haberse considerado ilícita la huelga, y su participación en la misma ilegal también, conforme a la ley del lugar donde se desarrolló la acción (Gabón y Sudáfrica). Es el mismo caso que resuelve nuestro Tribunal Supremo en sentencia de 27 de noviembre de 1982, aplicando las normas de orden público del país donde se realiza la huelga (Sudáfrica), considerada conforme a su ordenamiento un acto prohibido. Coinciden ambas en obviar el carácter de normas de orden público de la legislación francesa y espańola en materia de huelga, que hubiera impedido legitimar los efectos que la participación en las huelgas "ilícitas" tuvo en los contratos de trabajo.

(b) En el segundo caso, el empresario podrá reclamar la responsabilidad de los trabajadores o de los sindicatos. Así, reclamará por los daños y perjuicios causados por una acción colectiva que no está amparada por el derecho. Para determinar la ley aplicable a la responsabilidad por daños, el Reglamento no 864/2007, del Parlamento europeo y del Consejo, de 11 de julio de 2007, relativo a la ley aplicable a las obligaciones extracontractuales (Roma II) contiene, además de una regla de

\footnotetext{
53 Véase FOTINOPOULOU BASURKO, O., "La responsabilidad del sindicato en huelgas transnacionales (Primera parte)", Tribuna Social, no 238, 2010, pág. 51.

${ }^{54}$ Véase un listado en CARBALLO PIÑEIRO, ibidem, pág. 269, notas a pie 156, 157 y 160. También LAURICHESSE, C., La grève en droit internationale privé, Droit. Université de Bourgogne, 2014, <NNT: 2014DIJOD008> pág. 107.

55 Véase un ejemplo de ello en la sentencia del Tribunal Supremo español de 27 de noviembre de 1982, considerando la prohibición de la huelga en la República de Sudáfrica como norma de orden público aplicable en el lugar de trabajo.

56 Véase LABORDE, "Les rapports collectifs de travail en droit internationale privé ", cit., pp. 157-158.

${ }^{57}$ Decisiones de la Cour de Cassation, de 17 junio 1982 y 16 junio 1983 (también sobre la República de Sudáfrica).
} 
libertad de elección en el artículo 14 que resulta plenamente aplicable en estos supuestos $^{58}$, una norma de conflicto especial en su artículo $9^{59}$, donde establece que "la ley aplicable a una obligación extracontractual respecto de la responsabilidad de una persona en calidad de trabajador o de empresario o de las organizaciones que representen sus intereses profesionales por los daños causados por una acción de conflicto colectivo futura o realizada, será la ley del país en el que se haya emprendido la acción o vaya a emprenderse" (locus actus o lex loci actus), salvo que, "cuando la persona cuya responsabilidad se alega y la persona perjudicada tengan su residencia habitual en el mismo pais en el momento en que se produzca el daño, se aplicará la ley de dicho país" (artículo 4.2 Reglamento Roma II).

Lo que este último artículo no resuelve es qué sucede cuando hay múltiples sujetos que causan el daño, o más de una víctima de la acción colectiva con lugar de residencia en países diferentes, lo que podría dar lugar a la aplicación del foro por conexidad del artículo 8.1 Reglamento Bruselas I bis. En estos casos, la doctrina ${ }^{60}$ considera que este tipo de acción colectiva no sólo requiere un alto grado de previsibilidad respecto de la ley aplicable sino también que todas las partes implicadas sean capaces de coordinar su acción. Y para hacer esto es preciso, o deseable al menos, que todos puedan basarse en el mismo sistema legal para determinar la licitud o ilicitud de la acción.

En definitiva, para determinar la ley aplicable a la responsabilidad por daños provocados por una acción de conflicto colectivo, las reglas serán: en primer lugar, la libertad de elección conforme al artículo 14 del Reglamento Roma II ("las partes podrán convenir someter la obligación extracontractual a la ley que elijan: a) mediante un acuerdo posterior al hecho generador del daño... La elección deberá manifestarse expresamente o resultar de manera inequivoca de las circunstancias del caso y no perjudicará los derechos de terceros"); en segundo lugar, en defecto de elección se aplicará el artículo 4.2 del Reglamento, que vela por la aplicación, en ciertos supuestos, de la ley del país de residencia común de las partes del litigio; y por último, en caso de que ninguna de las dos reglas anteriores entre en juego, se aplicará lo previsto en la regla especial del artículo 9, esto es, la ley del país en que la acción colectiva se lleva a cabo o va a emprenderse ${ }^{61}$.

Debe tenerse en cuenta por último que, al igual que sucede con las obligaciones contractuales, el artículo 16 del Reglamento Roma II establece que lo previsto en el Reglamento no afecta a la aplicación de las disposiciones de la ley del foro que tengan carácter imperativo, cualquiera que sea la ley aplicable a la obligación extracontractual. En definitiva, el precepto contempla la aplicación en estos supuestos de las leyes de policía, esto es, de aquellas normas consideradas tan importantes para un Estado que este exige su aplicación en cuanto la situación jurídica litigiosa presenta un vínculo con su territorio, cualquiera que sea la ley aplicable al contrato, siendo entonces aplicadas tales normas de oficio por el juzgador ${ }^{62}$. Y, por su parte, el artículo 26 también contempla la posibilidad de excluir la aplicación de una disposición de la ley aplicable conforme al Reglamento si dicha aplicación es manifiestamente incompatible con el orden público del foro.

\footnotetext{
${ }^{58}$ Una crítica a su aplicación, en REQUEJO ISIDRO, M., "Elección de ley aplicable y responsabilidad contractual: ¿̨cambio de orientación en el modelo conflictual?", Revista de Derecho, no 8 (noviembre 2013), pág. 222.

${ }^{59}$ Un análisis detallado en FOTINOPOULOU BASURKO, O., "La responsabilidad del sindicato en huelgas transnacionales (Segunda parte)", Tribuna Social, no 239, 2010, págs. 39-47.

${ }^{60}$ DORSSEMENT y VAN HOEK, “Collective action in labour conflicts under the Rome II Regulation (Part II)”, cit., pág. 109.

${ }^{61}$ Evidentemente, hay supuestos en los que esta regla no parece la más adecuada. Al respecto puede verse FOTINOPOULOU BASURKO, "La responsabilidad del sindicato en huelgas transnacionales (Segunda parte)", cit., pág. 42.

${ }^{62}$ Puede verse este concepto de ley de policía en el Libro Verde sobre la transformación del Convenio de Roma de 1980 sobre la ley aplicable a las obligaciones contractuales en instrumento comunitario y sobre su actualización, COM (2002) 654 final, pág. 36.
} 


\subsection{La aplicabilidad de la Directiva 96/71/CE a las relaciones colectivas de trabajo: las disposiciones de orden público}

La Directiva 96/71/CE, de 19 de diciembre de 1996, del Parlamento europeo y del Consejo, sobre el desplazamiento de trabajadores efectuado en el marco de una prestación de servicios, no es exactamente una norma de armonización de las condiciones de trabajo aplicables a los trabajadores desplazados temporalmente en el marco de una prestación de servicios transnacional en el espacio de la Unión Europea, ni una norma de conflicto. Su objetivo es garantizar la aplicación a estos trabajadores de unas condiciones de trabajo mínimas existentes en el Estado Miembro al que se desplazan, cualquiera que sea la legislación aplicable al contrato individual de trabajo, tratando con ello de evitar el dumping social entre empresas que actúen en el trafico jurídico dentro de la Unión Europea. Esta Directiva ha sido modificada por la Directiva (UE) 2018/957, de 28 de junio de $2018^{63}$, que en su artículo 3, relativo a su transposición y aplicación, reconoce a los Estados miembros, con fecha límite de 30 de julio de 2020, el deber de adoptar las disposiciones legales, reglamentarias y administrativas necesarias para dar cumplimiento a lo establecido en la presente Directiva, comenzando a aplicar dichas medidas a partir de dicha fecha. Hasta entonces, la Directiva 96/71/CE seguirá siendo aplicable en su redacción anterior a las modificaciones introducidas por la Directiva 2018/957.

Aunque el artículo 3.1 de la Directiva 96/71/CE no incluía a los derechos colectivos entre los derechos a garantizar por los Estados Miembros donde trabaje el trabajador desplazado en el marco de una prestación de servicios transnacional, sí era posible que las leyes de transposición nacionales de la Directiva añadieran a la enumeración de derechos individuales contenidos en ésta otros derechos colectivos, con base en su artículo 3.10, donde se señala que "la presente Directiva no impedirá que los Estados miembros, de conformidad con las disposiciones del Tratado, impongan a las empresas nacionales y a las empresas de otros Estados, por igual... condiciones de trabajo y empleo referidas a materias distintas de las enumeradas en el párrafo primero del apartado primero, en la medida en que se trate de disposiciones de orden público".

Como disposiciones de orden público deben entenderse las disposiciones obligatorias, que no se pueden derogar y que, por su naturaleza y objetivos, responden a las exigencias imperativas del interés público (STJUE de 19 de junio de 2008, asunto C-319/06, Comisión contra Luxemburgo). Ahora bien, la doctrina internacional privatista ${ }^{64}$ señala que no todas las normas de orden público interno, entendidas como el "conjunto de normas imperativas de un ordenamiento jurídico", pueden ser consideradas normas de orden público internacional, entendiendo como tales al "conjunto de normas imperativas de un ordenamiento juridico interno absolutamente irrenunciables, incluso en presencia de una situación privada internacional". Además, sostiene que no hay que confundir orden público con leyes de policía. Para dicha doctrina, la excepción de orden público internacional es un mecanismo de protección de los principios jurídicos del foro que se consideran fundamentales, pero sólo actúa como reacción ante el contenido de una ley extranjera una vez ha entrado en juego la norma de conflicto, mientras que las leyes de policía no se aplican como reacción frente al contenido de una ley extranjera sino por la "imperatividad particular de la ley del foro".

En nuestro caso, el derecho de libertad sindical, el derecho de negociación como integrante del contenido esencial de la primera, el derecho de huelga como medida de conflicto, todos ellos se consideran materia de orden público. Así, la Ley española 45/1999, de 29 de noviembre, de desplazamiento de trabajadores en el marco de una prestación de servicios transnacional, incorporó en su artículo 3.1, junto a los derechos enumerados por la Directiva, los referidos a la "libre sindicación y

\footnotetext{
${ }^{63}$ DOUE núm. L 173, de 9 de julio de 2018.

${ }^{64}$ CALVO CARAVACA, A.L., "El Reglamento Roma I sobre la ley aplicable a las obligaciones contractuales: cuestiones escogidas", Cuadernos de Derecho Trasnacional, Vol. 1, no 2, 2009, pág. 116.
} 
los derechos de huelga y de reunión". Algo parecido sucede, por ejemplo, con el Code du Travail francés, que reconoce expresamente el ejercicio del derecho de huelga entre las materias incluidas en el listado (Art. L. 1262-4).

Así pues, si el ejemplo de la legislación española de transposición de la Directiva se encuentra generalizado entre los distintos Estados miembros de la Unión Europea, en aplicación del artículo 3.10 de la Directiva, el Estado miembro al que haya sido desplazado el trabajador, "cualquiera que sea la legislación aplicable a la relación laboral", garantizará a éste en su territorio los derechos colectivos de libertad sindical, huelga y reunión "que estén reconocidos" en su legislación. Ello no impedirá que, en todo caso, puedan aplicarse aquellas normas más favorables al trabajador derivadas de lo dispuesto en la legislación aplicable a su contrato de trabajo (artículo 7).

La Directiva 2018/957, por lo que respecta a la concreta materia de este trabajo, incorpora dos modificaciones del articulado de la Directiva 96/71/CE especialmente destacables. De un lado, introduce un nuevo apartado a su artículo 1, el 1 bis, con el siguiente tenor literal: "La presente Directiva no afectará en modo alguno al ejercicio de los derechos fundamentales reconocidos en los Estados miembros y a escala de la Unión, incluyendo el derecho o la libertad de huelga o de emprender otras acciones contempladas en los sistemas de relaciones laborales especificos de los Estados miembros, de conformidad con la legislación o las prácticas nacionales. Tampoco afecta al derecho a negociar, concluir y hacer cumplir convenios colectivos o llevar a cabo acciones colectivas conforme a la legislación o las prácticas nacionales". La doctrina ${ }^{65}$ lo ha considerado una toma de posición del legislador comunitario en busca del equilibrio entre las libertades comunitarias económicas de establecimiento y de prestación de servicios y los derechos de acción colectiva, puestos en cuestión a partir de las conocidas sentencias del TJUE en los casos Viking y Laval, si bien el mismo texto ya se encontraba incorporado en el artículo 1.2 de la Directiva 2014/67/UE, de 15 de mayo de 2014, relativa a la garantía de cumplimiento de la Directiva 96/71/CE.

De otro lado, la nueva Directiva 2018/957 reconoce a los trabajadores desplazados, no sólo las condiciones de trabajo que se establezcan, en el Estado miembro donde se efectúe el trabajo, a través de disposiciones legales, reglamentarias o administrativas, o convenios colectivos o laudos arbitrales declarados de aplicación universal, sino también, como novedad, las establecidas por convenios colectivos o laudos "de cualquier otro modo de aplicación". Es decir, habrán de respetarse también las condiciones de trabajo del país de acogida, aunque vengan establecidas por convenios que no sean de eficacia general o no gocen de aplicación universal, por utilizar la terminología usada por la Directiva, lo que podría quizás impedir a futuro decisiones como la adoptada por el TJUE en el Caso Ruffert.

Para finalizar, con relación a los derechos de representación de los trabajadores, aun cuando la ley española de transposición de la Directiva 96/71/CE no recoge la misma entre las materias a imponer a las empresas que desplazan temporalmente trabajadores a nuestro país, su Disposición Adicional $3^{\mathrm{a}}$ sí reconoce a los representantes de los trabajadores que hayan sido desplazados a España, y que ostenten la condición de representantes conforme a las legislaciones o prácticas nacionales, capacidad para ejercer acciones administrativas o judiciales en los mismos términos que la legislación española reconoce a los representantes de los trabajadores. Y otorga a los representantes de los trabajadores de las empresas usuarias y de las empresas que reciban en España la prestación de servicios de trabajadores desplazados, respecto de estos, las competencias que la legislación española les confiere, con independencia del lugar en que radique la empresa de trabajo temporal o la empresa prestataria de los servicios.

\footnotetext{
${ }^{65}$ Véase GARCIA MURCIA, J., "Dos nuevas Directivas de la Unión Europea en materia social: desplazamiento temporal de trabajadores y titulaciones profesionales", Foro Nueva Época, Vol. 21, no 1, 2018, pág. 333.
} 
Por su parte, la Directiva 2014/67/UE establece en su artículo 11.3 la obligación de los Estados miembros de garantizar que los sindicatos y otras terceras partes, como asociaciones, organizaciones y otras personas jurídicas que tengan un interés legítimo en velar por el cumplimiento de ambas Directivas puedan iniciar, en nombre y apoyo de los trabajadores desplazados o de sus empleadores, y con su autorización, acciones judiciales o administrativas con el fin de implementar las Directivas y garantizar el cumplimiento de las obligaciones que deriven de las mismas; ello "sin perjuicio de las normas procesales nacionales en materia de representación y defensa ante los tribunales y de las competencias y demás derechos que los sindicatos y otros representantes de los trabajadores tengan con arreglo al Derecho y las prácticas nacionales". La propia jurisprudencia comunitaria europea ha favorecido este ejercicio de acciones procesales por parte de los representantes sindicales en el marco de la Directiva 96/71, con apoyo en la tutela judicial efectiva del artículo 47 de la CDFUE ${ }^{66}$.

\section{Conclusiones}

Como ha podido observarse a lo largo del presente estudio, los derechos colectivos laborales y las relaciones entre los sujetos colectivos que representan a trabajadores y empresarios vienen regulados por los Estados a través de su legislación nacional con base, claramente, en un principio de territorialidad. Junto a ello, a diferencia de lo que ha sucedido con la relación individual de trabajo en la que existe un elemento internacional o de extranjería, el ejercicio extraterritorial de los derechos laborales colectivos ha carecido de tratamiento expreso, por parte del legislador comunitario, en lo relativo al establecimiento de unos criterios de conexión necesarios para determinar el órgano judicial competente para resolver los conflictos que se producen a raíz de tal ejercicio extraterritorial, pero también en lo relativo a la fijación de los criterios de conexión que permitan establecer cuál sea el ordenamiento jurídico aplicable al derecho en conflicto, cuando su ejercicio se produce extraterritorialmente.

Cuando nos referimos al ejercicio individual de los derechos colectivos, como pueda ser la participación del trabajador, sujeto de una relación de trabajo con elemento internacional, en una huelga en su lugar de trabajo, o la posible lesión de su derecho de libertad sindical, o la aplicación de convenio o acuerdo colectivo extranjero a su relación individual, se ha constatado que las normas de conflicto comunitarias resultan plenamente aplicables. No sucede lo mismo, sin embargo, con el ejercicio colectivo de tales derechos, algunos de los cuales se encuentran expresamente excluidos del ámbito de aplicación de las normas comunitarias. Por este motivo, en el trabajo se han intentado, de una parte, aportar soluciones razonadas para aquellos supuestos en los que resultan claramente inaplicables los reglamentos comunitarios; y, de otra, se ha tratado de argumentar la aplicación de dichos reglamentos en otros supuestos conflictivos en los que sí puede caber su empleo, aun cuando tales normas ni siquiera los mencionan.

Sin duda, una solución más fácil vendría dada por la reforma de las normas comunitarias en materia de competencia judicial y de legislación aplicable, para incorporar dentro de su ámbito de aplicación, de manera expresa, a los derechos laborales colectivos.

${ }^{66}$ Véase JIMENA QUESADA, L., "La protección constitucional de las relaciones laborales transnacionales en España”, Revista del Ministerio de Empleo y Seguridad Social, no 132, 2017, pág. 63, donde menciona, en tal sentido, la STJUE de 12 de febrero de 2015 (asunto C-396/13, Sähköalojen ammattiliitto ry). En el apartado 71 de la citada sentencia el Tribunal establece expresamente que, "en circunstancias como las del litigio principal, la Directiva 96/71/CE ... se opone a que una normativa del Estado miembro del domicilio de la empresa que ha desplazado trabajadores al territorio de otro Estado miembro (...) impida que un sindicato, como Sähköalojen ammattiliitto, interponga un recurso ante un órgano jurisdiccional del segundo Estado miembro en el que se ejecuta el trabajo, para cobrar en nombre de los trabajadores desplazados créditos salariales en relación con el salario minimo en el sentido de la Directiva 96/71 y que le han sido cedidos de conformidad con el derecho vigente en ese último Estado". 